\title{
Endoplasmic reticulum stress, hepatocyte CD1d and NKT cell abnormalities in murine fatty livers
}

\author{
Liu Yang ${ }^{1}$, Ravi Jhaveri' ${ }^{2}$, Jiawen Huang ${ }^{1}, \mathrm{Yi}^{\mathrm{Q}}{ }^{1}$ and Anna Mae Diehl ${ }^{1}$
}

The liver regulates lipid homeostasis and is enriched with natural killer T (NKT) cells that respond to lipid antigens. Optimal maturation and activation of NKT cells requires their interaction with lipid antigens that are presented by cluster of differentiation-1 (CD-1) molecules on antigen-presenting cells. Hepatocytes express CD1d and present lipid antigens to NKT cells. Depletion and dysregulation of hepatic NKT cells occurs in mice with fatty livers. Herein, we assess whether reduced CD1d content on steatotic hepatocytes contributes to fatty liver-associated NKT cell abnormalities. We show that despite expressing normal levels of CD1d mRNA, fatty hepatocytes from ob/ob mice have significantly less CD1d on their plasma membranes than normal hepatocytes. This has functional significance because ob/ob hepatocytes are less able to activate CD1d-restricted T-cell responses in vitro, and CD1d-reactive NKT cells are reduced in ob/ob livers. Events in the endoplasmic reticulum (ER) normally regulate CD1d trafficking to plasma membranes. Hepatic steatosis has been associated with ER stress. To determine if ER stress reduces CD-1 accumulation on hepatocytes, we evaluated hepatic ER stress in ob/ob mice and treated cultured hepatocytes and lean mice with tunicamycin to induce ER stress. Lipid accumulation and ER stress occurred in the livers of both ob/ob and tunicamycin-treated mice. Tunicamycin caused dose-dependent decreases in hepatocyte CD1d, inhibited hepatocyte activation of CD1d-restricted T-cell responses, depleted liver populations of CD1d-reactive NKT cells and promoted Th-1 polarization of hepatic cytokine production. In conclusion, ER stress-related decreases in hepatocyte CD1d contribute to NKT cell dysregulation in fatty livers.

Laboratory Investigation (2007) 87, 927-937; doi:10.1038/labinvest.3700603; published online 2 July 2007

KEYWORDS: cytokines; innate immunity; non-alcoholic fatty liver disease

The healthy liver houses many types of immune cells and the steady-state profile of immune cells in the liver differs markedly from that of secondary lymphoid organs and other non-lymphoid tissues. For example, the healthy liver contains large resident populations of macrophages and various types of T lymphocytes, natural killer (NK) cells and dendritic cells, but few, if any B cells. ${ }^{1-3}$ The liver is particularly enriched with natural killer T (NKT) cells, which are present at trace levels in blood and other organs. ${ }^{4,5}$ During development most NKT cells are generated in the thymus ${ }^{6-8}$ and migrate predominately into the liver, with lesser migration into certain other sites, such as bone marrow and spleen. ${ }^{9}$ In adults, resident NKT cells may self-renew. ${ }^{10}$ Circulating NKT cells also accumulate intrahepatically because they express chemokine receptor 6 (CXCR6) and receive viability signals from the CXCR6 ligand, chemokine receptor ligand 16, which is robustly expressed by hepatic sinusoidal endothelial cells. ${ }^{3}$ Intravital microscopy studies demonstrated that NKT cells, which account for most CXCR6 + cells in liver, crawl along hepatic sinusoids and stop upon activation of their T-cell receptor (TCR). ${ }^{3}$

Unlike the widely diversified TCRs of major histocompatibility complex (MHC) class I- and class II-restricted conventional T cells, which are activated by distinct peptide antigens, the TCR repertoire of NKT cells is fairly limited and responds exclusively to lipid antigens. ${ }^{11}$ In both mice and humans, the largest subset of NKT cells express a semi-invariant TCR, and a restricted V $\beta$-repertoire. Such cells are commonly referred to as classical, or TCR $\alpha$-invariant, NKT cells (iNKT). ${ }^{12}$ Nearly, all iNKT recognize the marinesponge-derived glycolipid $\alpha$-galactosyl ceramide ( $\alpha$ GalCer), presented in CD1d. ${ }^{13}$ Thus, CD1d tetramers loaded with $\alpha$ GalCer are often utilized to harvest iNKT cells from mice and humans. ${ }^{4,14}$

Native CD1d is a member of a family of MHC-like integral membrane proteins that are encoded by a locus of tightly

\footnotetext{
${ }^{1}$ Division of Gastroenterology, Department of Medicine, Duke University Medical Center, Durham, NC, USA and ${ }^{2}$ Department of Pediatrics, Duke University Medical Center, Durham, NC, USA

Correspondence: Dr AM Diehl, MD, Division of Gastroenterology, Department of Medicine, Duke University Medical Center, Suite 1073, GSRB no. 1595 LaSalle Street, Durham, NC 27710, USA. E-mail: annamae.dieh!@duke.edu
} 
clustered genes located on chromosome 1q23 in humans and on chromosome 3 in mice. ${ }^{15,16}$ Five cluster of differentiation1 (CD-1) genes, CD1A-E, have been identified in man, ${ }^{17-20}$ whereas mice contain only CD1D orthologs. ${ }^{15,16} \mathrm{CD}-1$ genes have been reported in many species, suggesting their preservation as a gene family in evolution. Various CD-1 isoforms are expanded or deleted in particular species, leading to speculation that each species has evolved CD-1 isoforms that follow distinct intracellular trafficking routes to sample antigens, even if it is not the same isoform in each species. $^{21,22}$ In both mice and humans, CD1d is thought to present endogenous glycolipid self-antigens to the iNKT cell TCR. ${ }^{23,24}$ Recent studies of mouse and human iNKT, TCRs reveal a contiguous conserved hot spot that provides the basis for the cross-species reactivity of NKT cells to CD1d-presented glycolipids. ${ }^{25}$

The fact that CD-1-restricted NKT cells respond to lipid, as opposed to peptide, antigens suggests that such cells may have been configured to accumulate preferentially in liver because hepatocytes are pivotal regulators of lipid intermediary metabolism. Indeed, although several types of liver cells express CD1d, the strongest CD1d expression in liver has been demonstrated on hepatocytes themselves. ${ }^{3}$ Intravital microscopy data suggest that hepatocytes are probably visited by four NKT cells $/ \mathrm{h},{ }^{3}$ demonstrating that patrolling NKT cells regularly survey CD1d-bound lipid antigens on hepatocyte plasma membranes. Despite recent work by Bendelac co-workers ${ }^{26}$ demonstrating that an endogenous lysosomal glycosphingolipid, iGb3, can activate NKT cells, the characterization of all of the endogenous glycolipid antigens remains incomplete.

However, it is known that CD1d traffics through cellular endolysosomal compartments and is likely loaded with its lipid antigen in the endoplasmic reticulum (ER) via a process that is mediated by microsomal triglyceride transfer protein (MTP). ${ }^{27}$

Lipid loading of CD1d influences subsequent trafficking of CD1d to the cell surface, because hepatocytes from MTP-deficient mice have a significantly reduced content of CD1d in their plasma membranes. ${ }^{27}$ Reduced cell surface expression of CD1d has functional implications, as evidenced by the diminished capacity of CD1d-deficient cells to activate TCR on NKT cell hybridomas. ${ }^{27}$ Other studies confirm that CD1d is a major regulator of NKT cell viability and function throughout life. For example, mice that are genetically deficient in CD1d are deficient in NKT cells because they cannot accomplish positive selection of NKT cell precursors by CD1d-expressing thymocytes during development. ${ }^{28}$ CD1d is also important in maintaining NKT cell homeostasis in adults, as demonstrated by evidence that immature NKT cells harvested from adults fail to fully mature when transferred to a CD1d-deficient environment. ${ }^{29}$ In addition, the level of CD1d expression correlates with the ability to activate NKT cells. Antigenpresenting cells expressing higher CD1d levels more efficiently activate NKT cell hybridomas and primary NKT cells. $^{30}$

Using methods that rely on NK1.1-immunoselection, we and others have reported that NKT cells are selectively depleted in the fatty livers of mice with genetic- or diet-induced obesity. ${ }^{31-33}$ These findings have important implications because liver is the primary reservoir for NKT cells in adults, and these cells regulate both innate and adaptive immune responses. ${ }^{4,5}$ Hence, depletion of hepatic NKT cells is predicted to have many, potentially deleterious consequences, ${ }^{31,32,34}$ including some that might contribute to the genesis of obesity-associated diseases, such as non-alcoholic fatty liver disease, autoimmunity and cancer. Because it has become evident that NK1.1 expression by NKT cells fluctuates according to their level of maturation and activation, ${ }^{35,36}$ interpretation of the initial finding of reduced NK1.1 (+) lymphocytes in obesity-associated fatty livers requires additional studies with tetramer-based methodologies that identify CD-1-restricted cells regardless of their level of NK1.1 expression. Also, it is important to determine if, and how, hepatic steatosis might influence the level of CD1d expressed by hepatocytes, since these cells function as important as antigen-presenting cells for CD1d-restricted iNKT cells.

Herein, we demonstrate that cell surface expression of CD1d is reduced in fatty hepatocytes and present evidence that an ER-stress-related mechanism is involved. Downregulation of CD1d expression in fatty hepatocytes is accompanied by functional consequences, including impaired activation of NKT cell hybridomas, reduced numbers of hepatic tetramer-reactive NKT cells, and Th-1 polarization of hepatic cytokine production. These findings complement and extend earlier evidence for NKT cell defects in fatty livers ${ }^{31-33}$ and have potential implications for the pathogenesis of other diseases that are strongly associated with hepatic steatosis, including diabetes and the metabolic syndrome.

\section{MATERIALS AND METHODS Animal Experiments}

Adult (age 10-12 weeks), male C57Bl-6 ob/ob and lean mice were purchased from Jackson Laboratories (Bar Harbor, ME, USA), maintained in a temperature- and light-controlled facility, and permitted ad libitum consumption of water and standard pellet chow. In initial acute studies, healthy lean C57Bl-6 mice were injected intraperitoneally (i.p.) with either tunicamycin (Calbiochem, San Diego, CA, USA) (400 ng/g body weight/day, $n=6$ mice) or phosphate-buffered saline (PBS) ( $n=4$ mice) for 4 days. Mice were killed and liver samples were collected on day 5 . Because treatment with $400 \mathrm{ng}$ tunicamycin/g body weight for 4 days resulted 33\% lethality, in subsequent longer-term studies mice $(n=$ 4/group) were treated with either PBS or a reduced dose of tunicamycin $(200 \mathrm{ng} / \mathrm{g}$ body weight $)$ by i.p. injection two times a week for 4 weeks. One day after the last dose of tunicamycin, the mice were injected i.p. with a single dose of 
Escherichia coli lipopolysaccharide (LPS) (Sigma Chemical, St Louis, MO, USA) (20 $\mu \mathrm{g} /$ mouse) or PBS and then killed after $6 \mathrm{~h}$ to obtain serum and liver tissue. Animal care and procedures were approved by the Duke University Medical Center Institutional Animal Care and Use Committee as set forth in the 'Guide for the Care and Use of Laboratory Animals' published by the National Institutes of Health.

\section{Cell Isolation and Cell Surface Labeling}

Hepatocytes were isolated by collagenase perfusion of the liver and centrifugal elutriation as described. ${ }^{37}$ The viability of all cells was verified by phase-contrast microscopy and the ability to exclude propidium iodide. The viability of all cell cultures utilized for study was $>90 \%$. For non-parenchymal cells, after in situ perfusion of the liver with $10 \mathrm{mg}$ pronase (Boehringer Mannheim, Indianapolis, IN, USA) followed by collagenase (Crescent Chemical, Hauppauge, NY, USA) as described, ${ }^{38}$ dispersed cell suspensions were layered on a discontinuous density gradient of 8.2 and $15.6 \%$ Accudenz (Accurate Chemical and Scientific, Westbury, NY, USA). Non-parenchymal cells containing endothelial cells and Kupffer cells in the lower layer were collected.

Hepatic mononuclear cells (HMNC) were isolated and labeled, using a minor modification of the method we described previously. ${ }^{31}$ Anti-mouse H2-D-PE, CD-1-FITC, CD3-FITC and CD4-APC were obtained from Pharmingen (San Diego, CA, USA). NKT cells were stained using $\mathrm{PE}-\mathrm{mCDd} / \mathrm{PBS} 57$ ligand tetramer (generously provided by the National Institute of Allergy and Infectious Disease MHC Tetramer Core Facility, Atlanta, GA, USA). ${ }^{39}$ Endothelial cells and Kupffer cells were labeled with anti-mouse CD31-PE (eBioscience, San Diego, CA, USA), F4/80-PE (Serotec, Oxford, UK) respectively. After surface labeling, cells were evaluated by flow cytometry (Becton Dickinson, Palo Alto, CA, USA). Data are analyzed by Cell Quest software (Becton Dickinson). To ascertain reproducibility of our findings, all flow cytometry studies were repeated at least three times. Data are shown as mean \pm s.e. percentage of positive cells from all of the experiments.

\section{Immunoblot}

Frozen liver samples and cells were homogenized in $150 \mu$ l of Dignam C buffer ${ }^{40}$ containing protease and phosphatase inhibitors as described. ${ }^{41}$ The homogenized samples were rotated on a tumbler for $30 \mathrm{~min}$ at $4^{\circ} \mathrm{C}$, and then centrifuged at 14000 r.p.m. for $5 \mathrm{~min}$ at $4^{\circ} \mathrm{C}$. The protein concentration of samples was determined using the Bio-Rad Protein Assay (Bio-Rad Laboratories, Hercules, CA, USA). Proteins (50 $\mu \mathrm{g}$ from whole liver) were separated by SDS-PAGE and then transferred to nitrocellulose (Schleicher and Schuell, Keene,

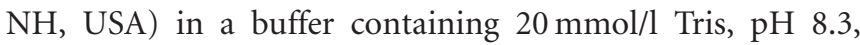
$150 \mathrm{mmol} / \mathrm{l}$ glycine, $0.01 \%$ SDS and $20 \%$ methanol. Equal loading of the gel was confirmed by staining nitrocellulose membranes with Ponceau S. After blocking with 5\% nonfat milk (Carnation, Swampscott, MA, USA) in Tris-buffered saline $(20 \mathrm{mmol} / \mathrm{l}$ Tris, $\mathrm{pH} 7.5,150 \mathrm{mmol} / \mathrm{l} \mathrm{NaCl})$ containing $0.1 \%$ Tween-20 (TBS-T) for $1 \mathrm{~h}$, nitrocellulose membranes were incubated with primary antibody anti-glucose regulated/binding immunoglobulin protein-78 (Grp-78) (Stressgen, Victoria, Canada) or $\beta$-actin antibody (Sigma, St Louis, MO, USA), all diluted 1:1000 in 5\% nonfat milk for $1 \mathrm{~h}$ (or in the case of immunoblotting involving whole liver extracts, for $12 \mathrm{~h}$ ), and then washed three times in TBS-T. Secondary antibody (horseradish peroxidase-conjugated anti-mouse IgG and anti-rabbit from Amersham, UK), was incubated with nitrocellulose membranes at a dilution of 1:1000 in 5\% nonfat milk for $30 \mathrm{~min}$. After four washes in TBS-T, antibody complexes were detected using the Amersham ECL system in linear range.

\section{Cell Culture and Antigen Presentation Assays}

AML-12 cells were grown in 1:1 mixture of DME/Ham's F-12 medium supplemented with $10 \%$ fetal bovine serum and antibiotics. DN32.IF3 cell were kindly provided by Dr Albert Bendelac. AML-12 hepatocytes or primary hepatocytes in 96-well plate $\left(1 \times 10^{4} /\right.$ well $)$ were loaded overnight with either vehicle or $100 \mathrm{ng} / \mathrm{ml} \alpha$-GalCer (AXXORA, San Diego, CA, USA), washed three times in PBS followed by the addition of $5 \times 10^{4}$ DN32.IF3 cells/well. Mouse interleukin-2 (IL-2) and interferon- $\gamma$ (IFN- $\gamma)$ production were assessed by ELISA (OptEIA, BD Pharmingen) after $24 \mathrm{~h}$.

\section{Tissue Triglyceride Assay}

Extraction of liver triglycerides with chloroform/methanol was modified by Burant et al. ${ }^{42}$ The triglyceride content was determined using Triglyceride Detection Kit Sigma.

\section{mRNA Quantification by Real-Time PCR and Semiquantitative PCR}

Total RNA was extracted from different type cells or whole livers using TRIzol (Invitrogen, Carlsbad, CA, USA). One microgram of RNA was reverse-transcribed using random primer and Superscript RNase H-reverse transcriptase (Invitrogen). Reverse transcription reactions contained $1 \mu \mathrm{g}$ of total RNA in a reaction mixture containing $25 \mathrm{mmol} / \mathrm{l}$ Tris- $\mathrm{HCl}, \mathrm{pH} 8.3,75 \mathrm{mmol} / \mathrm{l} \mathrm{KCl}, 3 \mathrm{mmol} / \mathrm{l} \mathrm{MgCl} 2,10 \mathrm{mmol} / \mathrm{l}$ DTT, $1.25 \mu \mathrm{g}$ oligo dT, $400 \mu \mathrm{mol} / \mathrm{l}$ each dNTP, and $20 \mathrm{U}$ RNase inhibitor (Gibco/BRRL, Rockville, MD). The reaction mixture was incubated at $68^{\circ} \mathrm{C}$ for $2 \mathrm{~min}$, and then placed on ice. Afterwards, $200 \mathrm{U}$ Moloney murine leukemia virus reverse transcriptase (RT) (GIBCO/BRRL, Rockville, MD) was added and the reaction incubated at $42^{\circ} \mathrm{C}$ for $1 \mathrm{~h}$.

For quantitative real time PCR, $1.5 \%$ of the first-strand reaction was amplified using iQ-SYBR Green Supermix (BioRad), an iCycler iQ Real-Time Detection System (Bio-Rad), and specific oligonucleotide primers for target sequences, as well as the $18 \mathrm{~S}$ housekeeping gene. The sequences of primers for mouse IL-4, tumor necrosis factor- $\alpha$ (TNF- $\alpha$ ), IFN- $\gamma$, IL-12 and $18 \mathrm{~S}$ are as follows: IL-4: sense: $5^{\prime}$-TCCTGCTCT TCTTTCTCG-3' ${ }^{\prime}$, antisense: $5^{\prime}$-CTTCTCCTGTGACCTCGT 
T-3', product size: 102 . IL-12 sense: 5'-GGAAGCACGGCAG CAGAATA- ${ }^{\prime}$, antisense: $5^{\prime}$-AACTTGAGGGAGAAGTAGGA ATGG-3', product size: 180 . IFN- $\gamma$ sense: $5^{\prime}$-CATCAGCAA CAACATAAGCGTCA- $3^{\prime}$, antisense: $5^{\prime}$-CTCCTTTTCCGCTT CCTGA- $3^{\prime}$, product size: 202 . TNF- $\alpha$ sense: $5^{\prime}$-TCGTAGCA AACCACCAAGTG-3' anti-sense: $5^{\prime}$-AGATAGCAAATCGG CTGACG-3', product size: 207. $18 \mathrm{~S}$ sense: $5^{\prime}$-TTGACG GAAGGGCACCACCAG-3', anti-sense: 5'-GCACCACCA CCCACGGAATCG- ${ }^{\prime}$, product size: 130 . The PCR parameters were as follows: denaturing at $95^{\circ} \mathrm{C}$ for $3 \mathrm{~min}$ followed by 40 cycles of denaturing at $95^{\circ} \mathrm{C}$ for $15 \mathrm{~s}$ and annealingextension at the optimal primer temperatures for 45-60 s. Threshold cycles $\left(C_{\mathrm{t}}\right)$ were automatically calculated by the iCycler iQ Real-Time Detection System. Target gene levels in the treated cells or tissues are presented as a ratio to levels detected in the corresponding control cells or tissues, respectively, according to the $\Delta \Delta C_{\mathrm{t}}$ method. These fold changes were determined using point and interval estimates.

For semiquantitative PCR, an aliquot of the reverse transcription reaction was used for PCR amplification using the reaction was cycled as follows: $94^{\circ} \mathrm{C}$ for $3 \mathrm{~min}$, then $94^{\circ} \mathrm{C}$ for $30 \mathrm{~s}, 55^{\circ} \mathrm{C}$ for $30 \mathrm{~s}$ and $72^{\circ} \mathrm{C}$ for $30 \mathrm{~s}$ for 25 cycles. PCR products were separated by electrophoresis on a $2.0 \%$ agarose gel. The PCR for both CD1d and CCAAT enhancer binding protein homologous protein $(\mathrm{CHOP})$ were determined to be within the linear range of amplification (data not shown). The sequences of primers for mouse CD1d, CHOP and glucuronidase (GUS) are as follows: CD1d sense: $5^{\prime}$-AATTA CACCTTCCGCTGCC- ${ }^{\prime}$ ', antisense: 5'-CAGTAGAGGATGA TATCCTG-3' ${ }^{\prime}$, product size: 818 ; GUS sense: $5^{\prime}$-GCAGTTG TGTGGGTGAATGG- $3^{\prime}$, antisense: $5^{\prime}$-GGGTCAGTGTGTTG TTGATGG-3', product size:142, CHOP sense: $5^{\prime}$ CCCTGCCT TTCACCTTGG3', Antisense: 5'CCGCTCGTTCTCCTGCTC ${ }^{\prime}$ product size: 371 .

\section{Statistical Analysis}

Results are expressed as mean \pm s.e.m. Significance was established using the Student's $t$-test. Differences were considered significant when $P<0.05$.

\section{RESULTS \\ Selective Hepatic CD4 + NKT Cell Depletion in ob/ob Mice}

We initially evaluated HMNC subtypes using cell surface markers and CD1d tetramers. Ob/ob mice had a significant decrease in tetramer-reactive hepatic NKT cells compared to lean mice (Figure 1a and b). The decrease in liver NKT cells was predominately attributable to reduced numbers of CD4 + NKT cells. This result is similar to our previous data acquired using CD3 and NK1.1 as NKT cell markers. ${ }^{31-33}$

\section{Decreased CD1d Expression on the Surface of ob/ob Hepatocytes}

CD1d expression on the surfaces of hepatocytes from ob/ob mice and their lean littermates was studied. We found that virtually all hepatocytes from lean mice expressed high surface levels of CD1d. In contrast, surface expression of CD1d was generally much lower on most ob/ob hepatocytes (Figure 2a). Also, the overall percentage of hepatocytes that were $\mathrm{CD} 1 \mathrm{~d}+$ was significantly reduced in ob/ob mice compared to lean mice (Figure $2 \mathrm{~b}$ ). We next tried to identify the reason why CD1d expression was decreased on ob/ob hepatocytes. RT-PCR was used to detect the mRNA level of CD1d in ob/ ob and lean hepatocytes. CD1d mRNA levels in ob/ob hepatocytes were not significantly different than in hepatocytes from lean controls (Figure 2c).

\section{No Significant Difference in CD1d Expression on the Surface of Endothelial and KUPFFER Cells of ob/ob and Lean Mice}

To determine if defects in surface CD1d expression were restricted to ob/ob hepatocytes, we investigated the CD1d expression on endothelial cells and Kupffer cells from both groups of mice. Endothelial cells and Kupffer cells were labeled with anti-mouse CD31-PE and F4/80-PE respectively. As reported previously, both cell types expressed CD1d. ${ }^{3}$ However, we found no significant difference in endothelial or Kupffer cell CD1d expression between lean and ob/ob mice (Figure 2d and e).

\section{Decreased ob/ob Hepatocyte Presentation of $\alpha$ GalCer to DN32.IF3 Cells}

To determine whether decreased CD1d influenced the ability of hepatocytes to activate invariant NKT cells, hepatocytes obtained from ob/ob or lean mice were co-cultured with DN32.IF3, a mouse CD1d-restricted invariant NKT cell hybridoma. In the absence of $\alpha \mathrm{GalCer}$, neither hepatocytes from lean nor ob/ob mice stimulated IL-2 release from the NKT hybridoma cells. However, IL-2 production increased substantially when $\alpha \mathrm{GalCer}$ was added to the co-cultures. Hepatocytes from lean mice stimulated DN32.IF3 cells to secrete IL-2 significantly more than hepatocytes from ob/ob mice (Figure 3), providing evidence that decreased CD1d on hepatocytes impairs regulation of CD1d-restricted T-cell responses. Under our assay conditions, neither hepatocytes from lean mice nor hepatocytes from ob/ob mice stimulated DN32.IF3 cell production of INF $\gamma$.

\section{Increased Endoplasmic Reticulum Stress in Livers of ob/ob Mice and Tunicamycin-Treated Mice}

Decreased hepatocyte CD1d surface expression and antigenpresenting function in ob/ob mice with fatty livers resemble findings in mice that are genetically deficient in MTP: ${ }^{27}$ the latter strain also has fatty livers, reduced expression of CD1d on hepatocyte surfaces, and impaired activation of CD1drestricted T-cell responses. To evaluate the possibility that MTP deficiency might underlie these abnormalities in ob/ob mice, we compared MTP activity in ob/ob and lean hepatocytes. Our results verified a previous report ${ }^{43}$ that MTP activity is actually increased in ob/ob mice (data not shown). 
a

Gate:

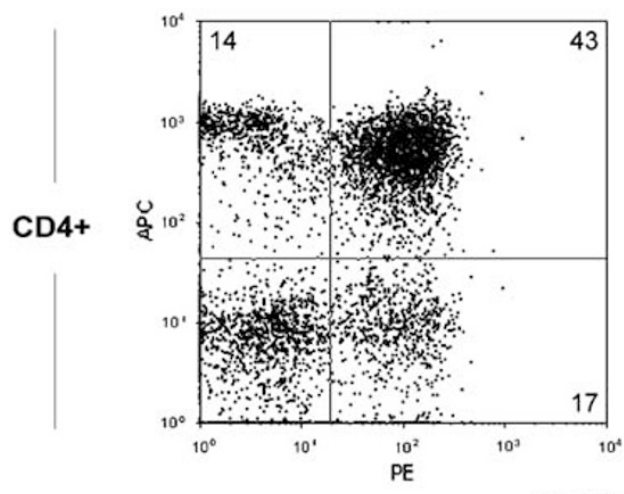

ob/ob

CD3

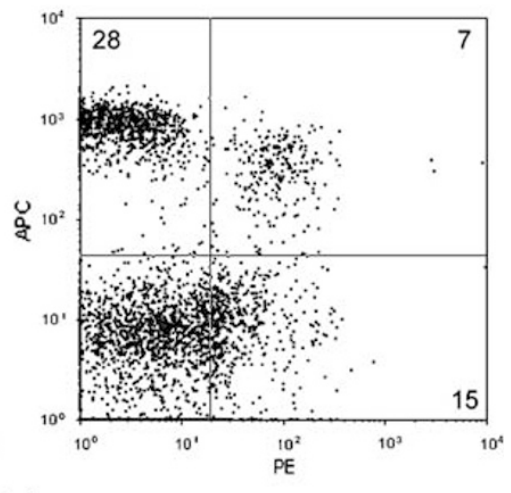

Figure 1 Distribution of CD1d tetramer-reactive liver mononuclear cells in ob/ob and lean C57BL6 mice. Mononuclear cells were isolated from the livers of ob/ob mice and lean mice. Purified mononuclear cell fractions were incubated with antibody to CD3, CD4 and CD1d tetramer. Fluorescence-activated cell sorting (FACS) analysis was used to determine the relative distribution of $\mathrm{CD} 4+\mathrm{CD} 1 \mathrm{~d}$ tetramer-reactive (ie, NKT) cells in the two groups of mice. The FACS result shown is representative of three independent experiments (a). Cumulative data are graphed (results expressed relative to number of CD1d tetramer-reactive cells that were also CD4 + in lean control livers. ${ }^{*} P<0.05$ compared to lean mice (b).

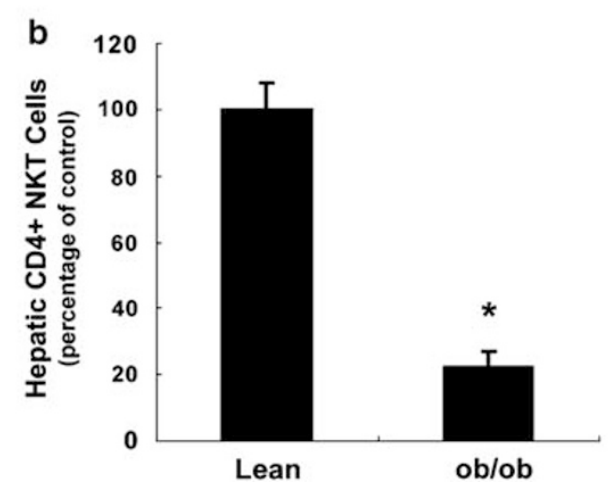

Thus, we explored alternative explanations for the CD1d defects in ob/ob mice. Given evidence that MTP-mediated events in the ER regulate trafficking of CD1d to hepatocyte plasma membranes as well as secretion of lipoproteins, we wondered if other types of ER dysfunction, such as ER stress, might dysregulate CD1d.

First, we examined whether hepatic ER stress was increased in ob/ob mice. To do this, we investigated the expression patterns of CHOP and GRP-78 (Bip) by RT-PCR and western blot, respectively. CHOP mRNA levels were higher in ob/ob mice than in lean mice (Figure 4a). The $78-\mathrm{kDa}$ GRP-78 is an ER chaperone whose expression is increased upon ER stress. ${ }^{44}$ As others have reported, ${ }^{45}$ GRP-78 (Bip) protein levels were elevated in livers of the obese mice compared with lean controls (Figure $4 \mathrm{~b}$ ). For comparison, we examined these ER stress markers in tunicamycin-treated animals. Tunicamycin treatment has been well validated as an approach for inducing ER stress in hepatocytes. As expected, ${ }^{45} \mathrm{CHOP}$ and GRP-78 (Bip) were significantly increased after treatment of lean mice with tunicamycin (Figure $4 \mathrm{c}$ and $\mathrm{d}$ ).

\section{Decreased CD1d Expression and Antigen Presentation of AML-12 Hepatocytes after Treatment with Tunicamycin}

Given the correlation between fatty liver, ER stress and reduced surface expression of CD1d on hepatocytes in ob/ob mice, we next determined if a pharmacologic inducer of ER stress (eg, tunicamycin) decreased CD1d expression on the surface of non-steatotic hepatocytes. AML-12 hepatocytes were treated with vehicle or tunicamycin $(5.0 \mu \mathrm{g} / \mathrm{ml})$ for $48 \mathrm{~h}$. After discarding the medium, plates were washed to remove dead (non-adherent) cells, and then adherent (viable) cells were harvested and analyzed by flow cytometry to determine the percentage that were $\mathrm{CD} 1 \mathrm{~d}+$. Tunicamycin treatment significantly decreased the percentage of CD1d + AML-12 hepatocytes (Figure 5a). In contrast, growing AML-12 cells in high insulin medium with dexamethasone for $48 \mathrm{~h}$ to induce triglyceride accumulation (Figure $5 \mathrm{~b}$ and $\mathrm{c}$ ) had no significant effect on surface CD1d expression (Figure 5a). Therefore, ER stress, rather than triglyceride accumulation per se, acutely inhibited surface CD1d expression on cultured hepatocytes.

We next examined whether ER stress influenced the ability of hepatocytes to activate invariant NKT cells. AML-12 hepatocytes were treated with a range of tunicamycin doses $(0,0.5,1$ or $5 \mu \mathrm{g} / \mathrm{ml}$ ) for $24 \mathrm{~h}$, tunicamycin-containing medium was removed, the cultures were washed three times to remove non-adherent (dead) cells, and then the remaining adherent (viable) cells were co-cultured with DN32.IF3 hybridoma cells in the presence of $\alpha$-galactosylceramide ( $\alpha$ Galcer) to evaluate CD1d antigen presentation. Tunicamycin pre-treatment resulted in a dose-dependent decrease in the ability of 
a

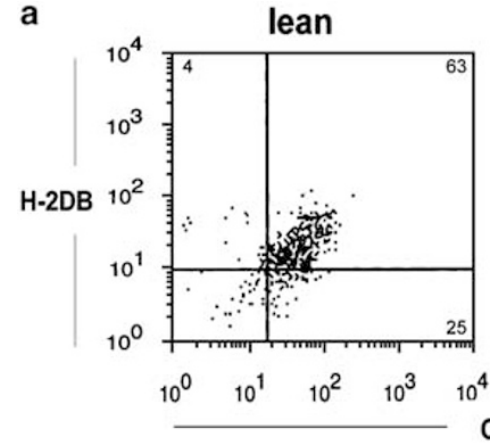

c

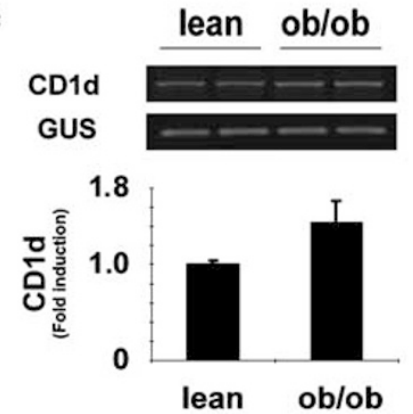

ob/ob

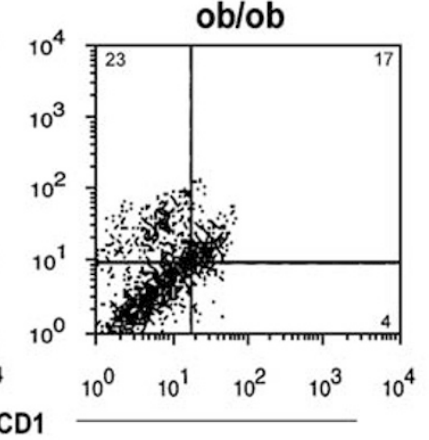

d

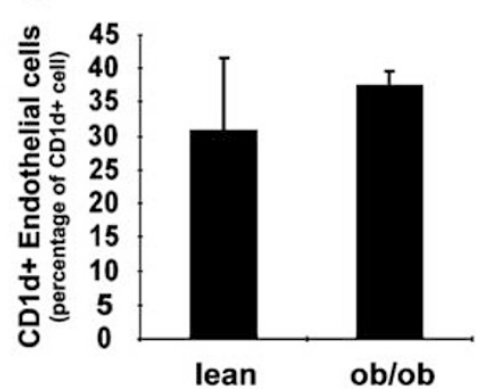

b

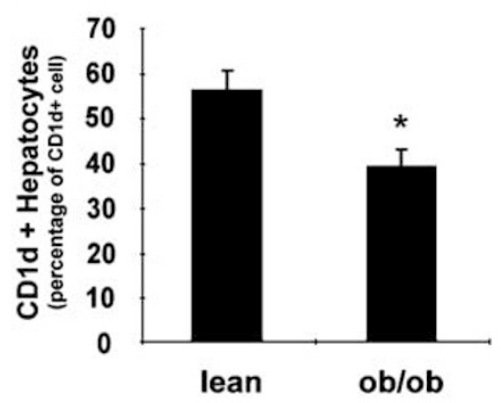

e

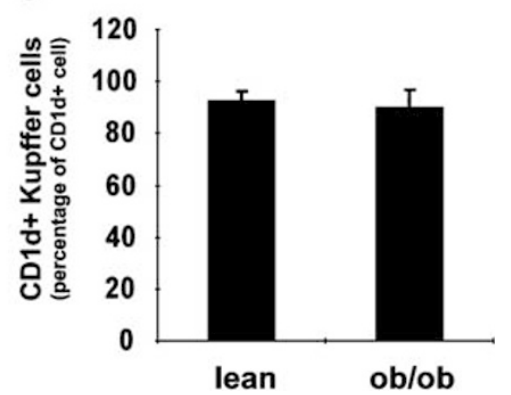

Figure 2 Percentage of CD1d + cells in hepatocyte, endothelial cell and Kupffer cell fractions from ob/ob and lean mouse livers. Hepatocytes and liver non-parenchymal cells were isolated. Hepatocytes were incubated with antibody to CD-1 and H2-Db, an MHC class-1 molecule. Results of a representative FACS analysis of CD1d + hepatocytes in the two groups of mice (a). The percentage of hepatocytes that were CD1d + was analyzed in a total of four independent experiments. Cumulative data are graphed $\left({ }^{*} P<0.05\right.$ compared to lean mice, $\left.n=4\right)(\mathbf{b})$. CD1d expression was also evaluated by RT-PCR analysis of total RNA isolated from lean and ob/ob hepatocytes. GUS was detected in the same CDNA sample and used as an internal control. The RT-PCR gel shown is representative of findings in four independent experiments. Cumulative data are graphed (c). Liver non-parenchymal cells were incubated with anti-mouse CD1d-FITC. Endothelial cells and Kupffer cells were labeled with anti-mouse CD31-PE and F4/80-PE respectively. In each group of mice, the percentage of each cell type that was CD1d + is shown for endothelial cells (d) and Kupffer cells (e).

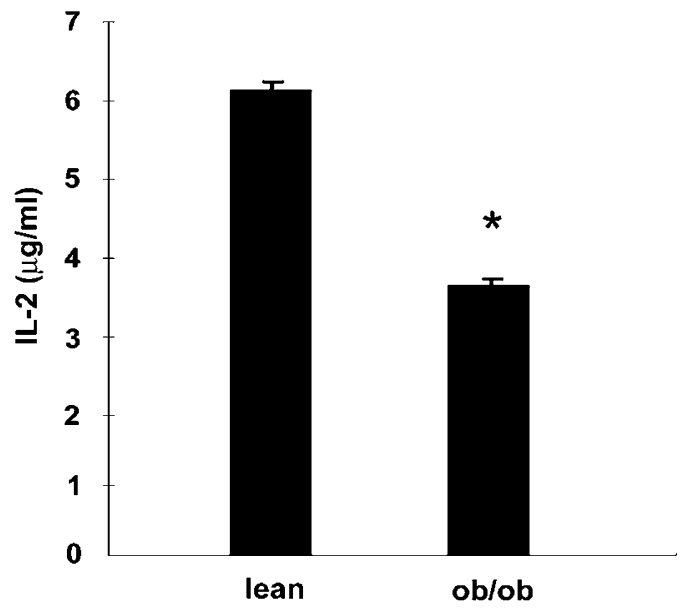

Figure 3 CD1d antigen presentation by ob/ob and lean hepatocytes. Hepatocytes were isolated from ob/ob and lean livers and then incubated with DN32.IF3 NKT hybridoma cells in the absence or presence of $\alpha$ GalCer $(100 \mathrm{ng} / \mathrm{ml})$. Efficacy of hepatocyte antigen presentation was assessed by quantifying induction of IL-2 production by the NKT hybridoma cells. DN32.IF3 cell production of IL-2 was no different than basal levels when the hybridoma cells were incubated with either ob/ob or lean hepatocytes in the absence of $\alpha$ GalCer. However, addition of $\alpha$ GalCer triggered substantial IL-2 production. Results of four independent experiments are graphed $\left({ }^{*} P<0.05\right.$ compared to lean mice, $\left.n=4\right)$.
AML-12 cells to stimulate DN32.IF3 cell secretion of IL-2 in the presence of $\alpha \mathrm{GalCer}$ (Figure $5 \mathrm{~d}$ ). Interestingly, the $5 \mu \mathrm{g} / \mathrm{ml}$ dose of tunicamycin that caused about a $40-50 \%$ decrease in the percentage of $\operatorname{CD} 1 \mathrm{~d}(+)$ hepatocytes (Figure 5a) virtually abolished hepatocyte induction of NKT hybridoma cell production of IL-2 (Figure 5d), suggesting that relatively small decrements in surface CD1d content on hepatocytes may result in profound impairment of certain NKT cell functions. Thus, pharmacologic induction of ER stress decreased CD1d on surfaces of otherwise healthy hepatocytes and this impaired hepatocyte regulation of CD1d-restricted NKT cell responses.

Tunicamycin Decreased Hepatic CD4 + NKT Cells In Vivo To assess the effect of ER stress on NKT cell accumulation in intact mice, healthy lean, 6-week-old C57Bl-6 mice were injected with tunicamycin ( $400 \mathrm{ng} / \mathrm{g}$ body weight/day) or PBS i.p. for 5 days. PBS-treated mice had normal liver histology (Figure 6a), whereas mice treated with tunicamycin developed hepatic steatosis (Figure 6b). Biochemical assays confirmed that tunicamycin increased liver triglyceride content by about two-fold (Figure 6c). Interestingly, hepatic CD4+ NKT cells were significantly decreased in livers of tunica- 
a

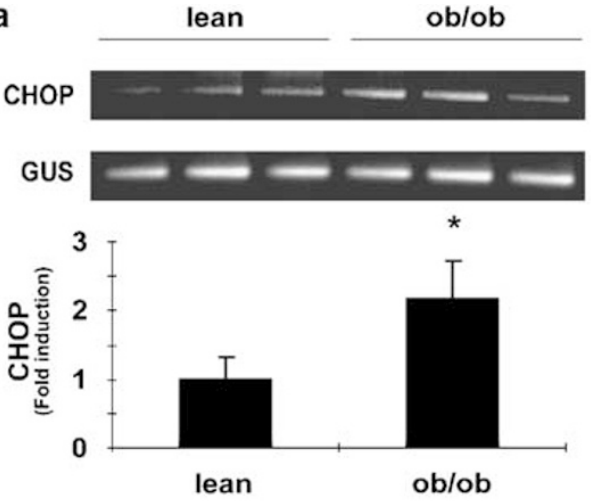

C
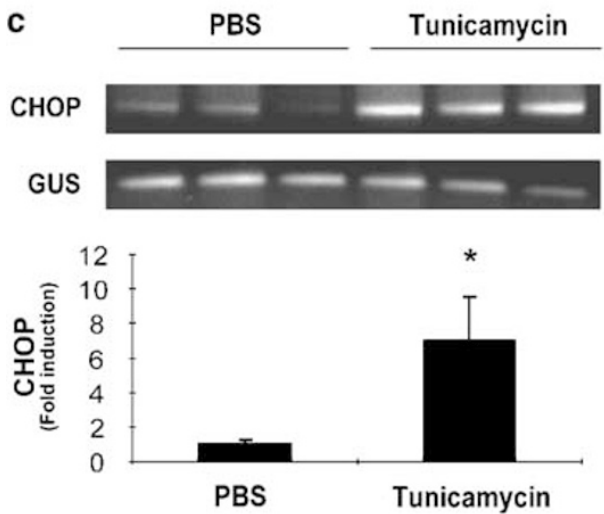

b
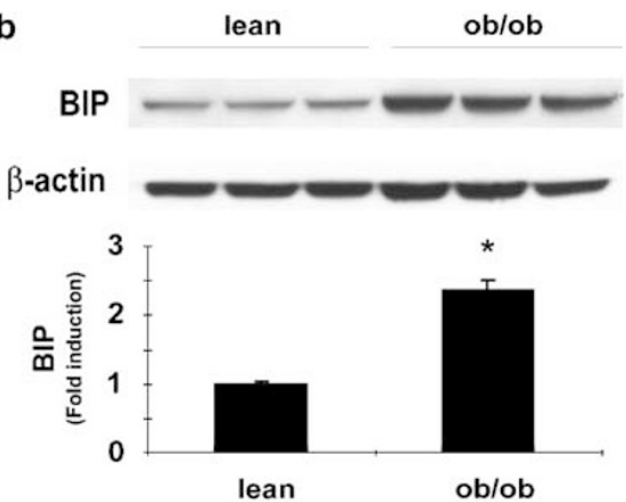

d

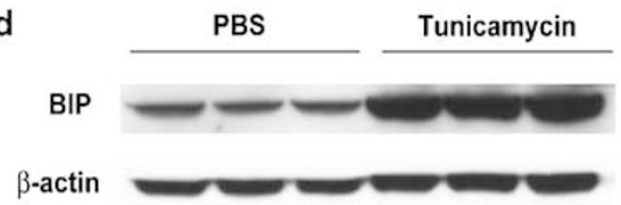

Figure 4 Markers of ER stress in ob/ ob mice, tunicamycin-treated mice, and respective controls. Total liver RNA and protein were isolated from lean and ob/ob mice, and also from wild-type mice treated with saline vehicle or tunicamycin. CHOP was detected by RT-PCR; GUS was detected in the same cDNA sample and used as an internal control (a and c). Bip was detected in total liver protein by immunoblotting; $\beta$-actin was detected on the same blot and used as a loading control (b and $\mathbf{d}$ ). The RT-PCR and immunoblots shown are representative of three independent experiments. Cumulative data are graphed.

mycin-treated mice compared to the livers of saline-treated controls (Figure $5 \mathrm{~d}$ ). In contrast, tunicamycin treatment did not decrease other T-cell populations. In fact, hepatic populations of both CD4 $(+)$ and CD4 $(-)$ conventional T cells tended to be higher in tunicamycin-treated mice than controls (Figure 6e and f). Hence, inducing ER stress in healthy lean mice caused hepatic steatosis and selectively reduced resident populations of CD1d-restricted of hepatic $\mathrm{T}$ cells.

\section{Th-1 Polarization of Hepatic Cytokine Production in Tunicamycin-Treated Mice with Reduced Hepatic CD4 + NKT Cells}

CD4 + NKT cells perform important immunoregulatory functions, including modulation of cytokine production by many other types of cells. ${ }^{46,47}$ To determine if tunicamycinmediated alterations in hepatic NKT cells populations were accompanied by differences in hepatic cytokine profiles, real time RT-PCR analysis of liver RNA from tunicamycin-treated and control mice was performed. Tunicamycin treatment increased basal expression of Th-1 cytokines, including TNF$\alpha$ and IFN- $\gamma$ (Figure $7 \mathrm{a}$ and $\mathrm{b}$ ), while levels of the Th-2 cytokine, IL-4, tended to decrease (Figure 7c). Such Th-1 polarization of hepatic cytokine production resulted in increased expression of pro-inflammatory cytokines, such as IL-12, when tunicamycin-treated mice were challenged with LPS (Figure 7d).

\section{DISCUSSION}

Earlier, we demonstrated reduced numbers of NK1.1 $(+) \mathrm{T}$ cells in the fatty livers of mice with genetic- or diet-induced obesity and the metabolic syndrome. ${ }^{31,32}$ Although NK1.1 expression may vary during the course of NKT cell maturation and activation, virtually all NKT cells react to the glycolipid, $\alpha$ GalCer, presented by CD1d. ${ }^{48}$ The present study shows that, like NK1.1 $(+)$ cells, tetramer-reactive cells are significantly reduced in the fatty livers of genetically obese, leptin-deficient ob/ob mice. Similar reductions were noted in wild-type mice with high-fat diet-induced obesity, hyperleptinemia/leptin resistance and fatty livers. Others recently reported defective in vitro activation of NKT cells by fatty hepatocytes from mice with an intact leptin axis but genetic deficiency of MTP, an ER protein that mediates lipoprotein assembly and secretion. ${ }^{27}$ Thus, NKT cell depletion/dysfunction appears to be a common feature of fatty livers, occurring in mice with genetic obesity (eg, ob/ob mice) and diet-induced obesity (eg, high-fat diet fed mice).

This finding raises questions about the role of hepatocyte lipid accumulation in regulating NKT cells. Hepatocytes are known to express CD1d, ${ }^{3,27}$ the MHC-like molecule that presents lipid antigens to NKT cell TCRs. CD-1 isoforms are thought to acquire endogenous lipid antigens as they traffic through cellular endolysosomal compartments, ${ }^{1}$ and recent studies in MTP-deficient cells and mice demonstrated that 

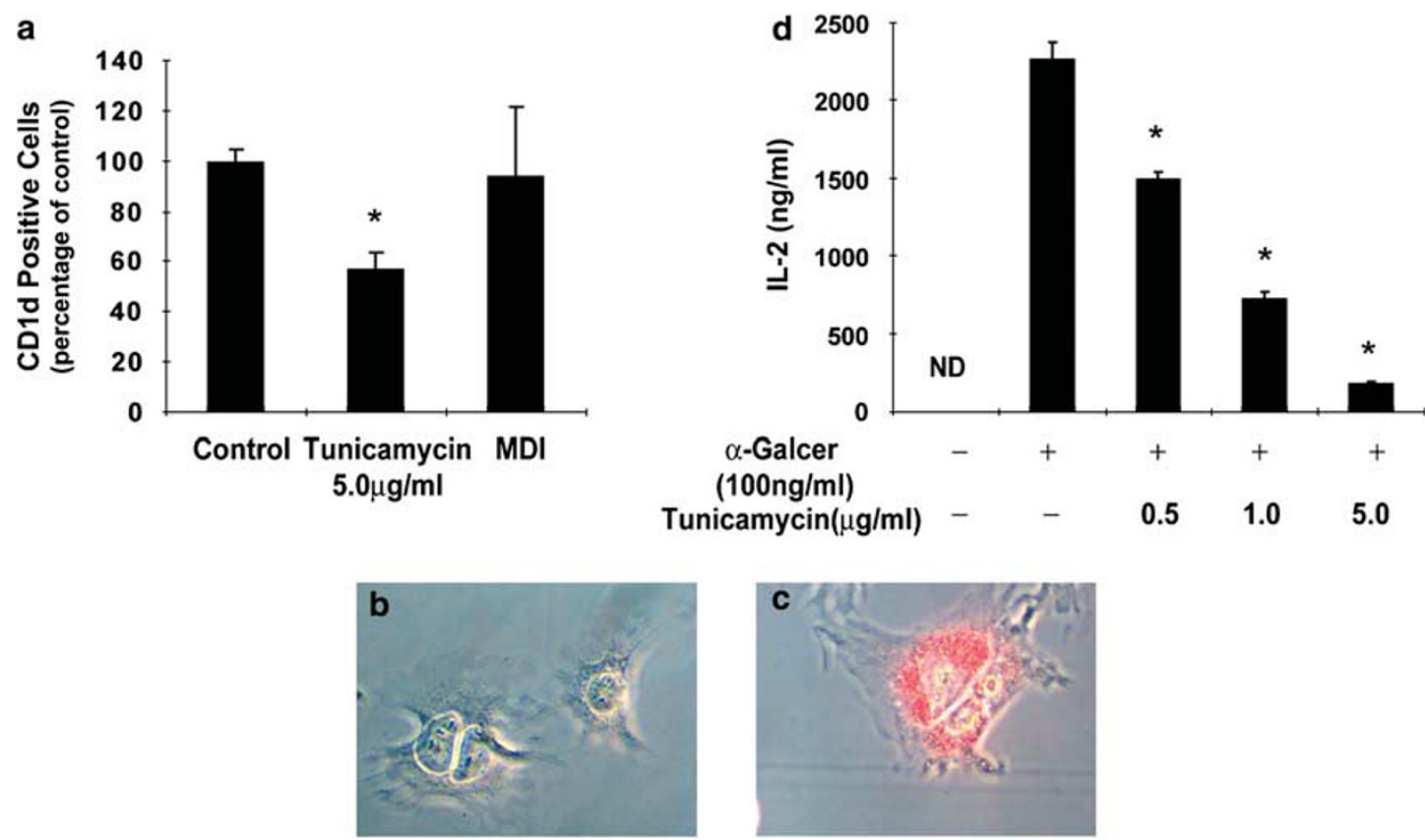

Figure 5 Decreased CD1d expression and antigen presentation by AML-12 hepatocytes after treatment with Tunicamycin. AML-12 hepatocytes were cultured in serum supplemented DME/Ham's F-12 medium and treated with vehicle (control) or tunicamycin $(5.0 \mu \mathrm{g} / \mathrm{ml})$ for $48 \mathrm{~h}$, or cultured in isobutylmethylxanthine, dexamethazone and insulin-containing medium (MDI) and treated with vehicle, but no tunicamycin, for $48 \mathrm{~h}$. After washing the cultures to remove medium and non-adherent (dead) hepatocytes, hepatocytes were harvested, stained with oil red $\mathrm{O}$ stain or incubated with anti-mouse CD1d-FITC, and analyzed by FACS. Results in each treatment group are expressed as percentage of hepatocytes that were CD1d + . Data from three independent experiments are graphed (a). Photomicrograph of representative, vehicle-treated AML-12 cell grown in DME/Ham's F-12 medium demonstrates few lipid droplets (b). Photomicrograph of representative, vehicle-treated AML-12 cell grown in MDI demonstrates cellular accumulation of lipid droplets (c). To evaluate the effect of tunicamyicin treatment on hepatocyte antigen presentation, experiments were repeated with AML-12 cells cultured in DME/Hams' F-12 medium. After treatment with a range of tunicamycin doses (0-5 $\mu \mathrm{g} / \mathrm{ml})$ for $48 \mathrm{~h}$, cultures were washed to remove medium and dead cells. The remaining viable AML-12 hepatocytes were incubated with DN32.IF3 NKT hybridoma cells in the absence or presence of $\alpha$ GalCer. AML-12 hepatocyte presentation of $\alpha$ GalCer was assessed by measuring DN32.IF3 cell IL-2 production (d) $\left({ }^{*} P<0.05\right.$ compared to control, ND, not detected).

events in the ER regulate subsequent delivery of lipid-loaded CD1d to hepatocyte plasma membranes. ${ }^{27}$

We found that the expression of CD1d is reduced on the surface of fatty hepatocytes from ob/ob mice, but not on endothelial or Kupffer cells that were harvested from the same livers. As was reported in MTP-deficient mice with fatty livers, ${ }^{27}$ reduced hepatocyte surface expression of CD1d occurred despite conserved levels of CD1d mRNA. However, MTP deficiency or dysfunction is not likely to explain decreased surface expression of CD1d or steatosis in ob/ob hepatocytes because MTP levels and very low-density lipoprotein secretion are known to be increased in these mice, ${ }^{43}$ and we demonstrated that MTP activity is actually higher in $\mathrm{ob} / \mathrm{ob}$ hepatocytes than in hepatocytes from their wild-type littermates.

MTP is an ER protein. CD1d is also known to interact with other ER proteins, including calnexin and calriticulin. The latter two ER proteins regulate ER quality control mechanisms by chaperoning proteins to assure proper folding. ${ }^{1}$ Given that ER events regulate appropriate trafficking of CD1d, we, therefore, considered alternative ER-related mechanisms that might disrupt both hepatocyte lipid homeostasis and
CD1d trafficking. Fatty livers caused by alcohol consumption, high-fat diet-induced obesity and obesity from inherited leptin deficiency have been associated with ER stress. ${ }^{45,49}$ To test whether or not ER stress is sufficient to disrupt hepatocyte lipid homeostasis and reduce CD1d expression on hepatocyte plasma membranes, we treated mouse hepatocytes and intact healthy, lean mice with tunicamycin. As expected, tunicamycin induced classical markers of ER stress, including CHOP and BIP. ${ }^{50}$ It also caused hepatic steatosis and produced a dose-dependent decrease in hepatocyte surface CD1d. This reduction in CD1d expression was paralleled by comparable decrements in hepatocyte activation of NKT cell hybridomas by $\alpha$ GalCer in vitro, as well as decreased numbers of CD1d-restricted cells in the livers of intact mice. Together, these findings suggest that hepatocyte ER stress contributes to both hepatic steatosis and altered homeostasis of hepatic NKT cell populations. The latter involves reduced accumulation of CD1d on hepatocyte plasma membranes.

Interactions with CD1d-presented lipid antigens regulate both the maturation and activation of NKT cells. Both processes are known to be impaired in the context of CD1d 

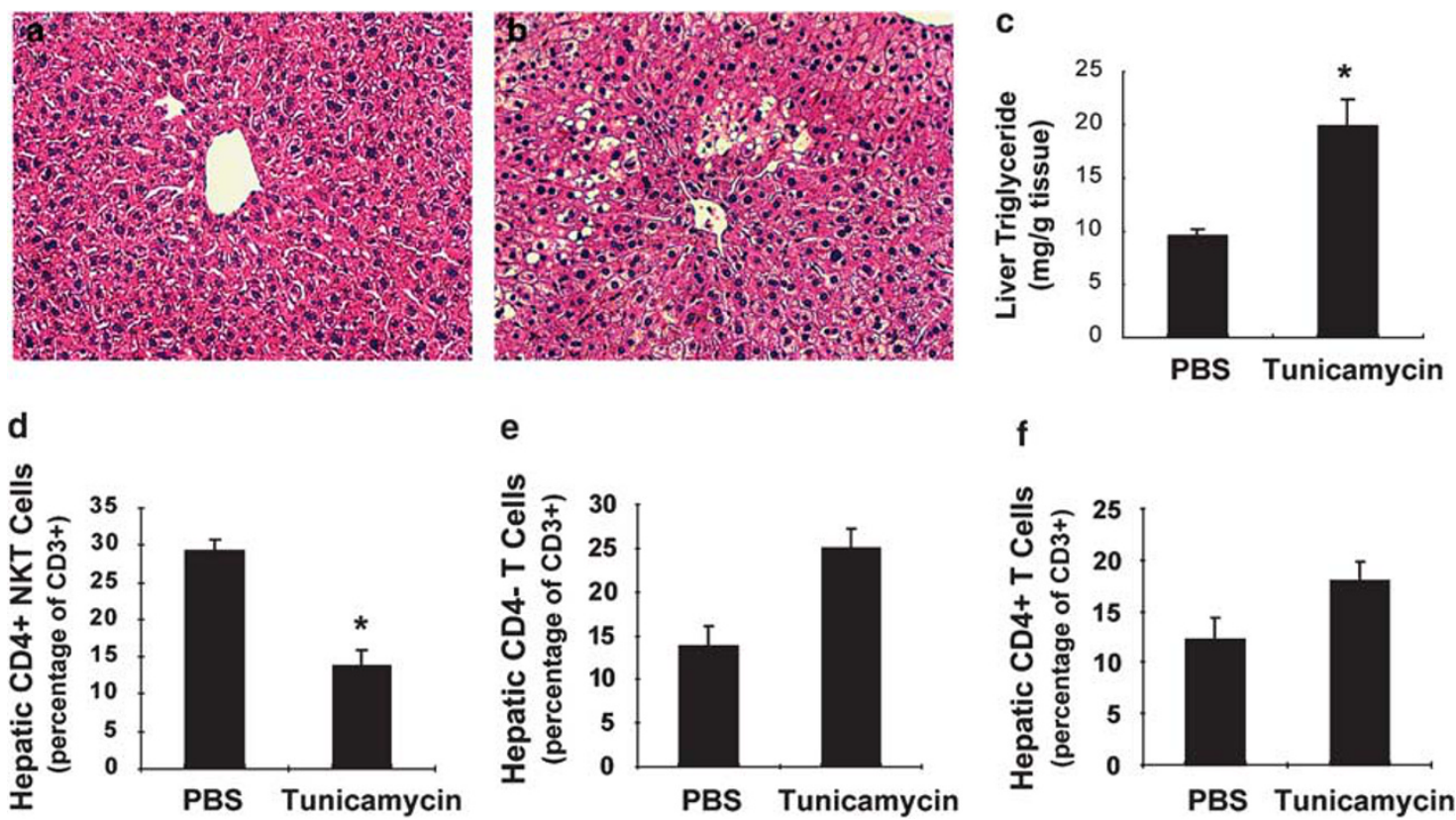

Figure 6 Tunicamycin, an ER stress-inducing agent, causes hepatic steatosis and reduces liver CD4 + NKT cells. Six-week-old healthy lean C57BI-6 mice were injected with tunicamycin $(400 \mathrm{ng} / \mathrm{g}$ body weight/day) or PBS i.p. for 5 days. Hematoxylin and eosin stained liver sections from representative from PBS-treated mice (a), and mice 5 days after tunicamycin treatment (b). Liver triglyceride content in all PBS- and tunicamycin-treated mice $(n=4 /$ group), $P<0.05$ vs PBS group (c). At the end of treatment, liver mononuclear cells were isolated from other mice in each group. Purified mononuclear cell fractions were harvested and analyzed by flow cytometry: CD4 + NKT cells (d), CD4- T cells (e) and CD4 + T cells (f) $\left({ }^{*} P<0.05\right.$ compared to PBS-injected mice, $n=4)$.

deficiency. ${ }^{28}$ We reported previously that NKT cell depletion resulted in Th1 polarization of hepatic cytokine production in ob/ob mice and wild type mice with diet-induced obesity. ${ }^{31,32}$ Both strains have also been shown to have fatty livers and hepatic ER stress. ${ }^{45}$ It is unclear which insult (ie, steatosis or ER stress) is primary in mice with fatty livers because steatosis promotes ER stress. ${ }^{45}$ However, in the present studies when we treated healthy, wild-type mice with tunicamycin to cause primary ER stress, the resultant outcomes included hepatic steatosis, decreased hepatocyte CD1d expression, depleted hepatic NKT cell populations and Th1 polarization of hepatic cytokines. Together, these data suggest that ER stress may trigger self-reinforcing mechanisms that contribute to both hepatic steatosis and innate immune dysfunction. Consistent with this concept, the livers of mice with tunicamycin-induced steatosis and NKT cell depletion expressed higher baseline mRNA levels of several Th-1 cytokines, including TNF- $\alpha$ and IFN- $\gamma$, that are known to exacerbate fatty liver damage. ${ }^{31,51}$ Also, similar to obese mice that are exquisitely sensitive to LPS-hepatotoxicity, ${ }^{31}$ tunicamycin-treated lean mice produced more pro-inflammatory cytokines, such as IL-12, when challenged with LPS. Hence, defects in the hepatic innate immune system generated a proinflammatory bias in local immune responses. Given the strong association between pro-inflammatory states and hepatic steatosis, ${ }^{31}$ the latter finding raises the intriguing possibility that hepatic NKT cell depletion per se might actually precipitate hepatic fat accumulation. This concept is sup- ported by a recent publication demonstrating that adoptive transfer of small numbers of NKT cells improved steatosis and insulin sensitivity in ob/ob mice. ${ }^{52}$ In any case, given that iNKT cell-derived cytokines rapidly instruct other cells that participate in subsequent innate and adaptive immune responses, ${ }^{1}$ these alterations in hepatic cytokine production are likely to have broad implications. Also, because iNKT cells are potently cytolytic, releasing perforin and granzymes and expressing membrane-bound Fas ligand like NK cells, ${ }^{53,54}$ decreases in hepatic iNKT populations might impair local clearance of tumor and microbial antigens.

At this point it is not clear to what extent, if any, ER stressrelated alterations in hepatic NKT cell homeostasis contribute to obesity-related morbidity and mortality in humans. Lean mice that chronically consume high-calorie diets become obese, and develop fatty livers, hepatic ER stress and reduced numbers of liver NKT cells. While overeating clearly promotes obesity and hepatic steatosis in humans, whether or not this is accompanied by hepatic ER stress or NKT cell depletion has not, to our knowledge, been investigated. Relative to murine livers in which iNKT cells are one of the predominant lymphocyte populations, human livers harbor fewer iNKT cells. ${ }^{14,55,56}$ Nevertheless, the liver remains the predominant locus for iNKT cells in both species. ${ }^{4,55}$ In addition, structural analysis of human and murine iNKT TCRs demonstrates conservation of domains that interact with CD1d-presented glycolipids, ${ }^{57}$ predicting cross-species reactivity to antigens that are presented to iNKT cells by 

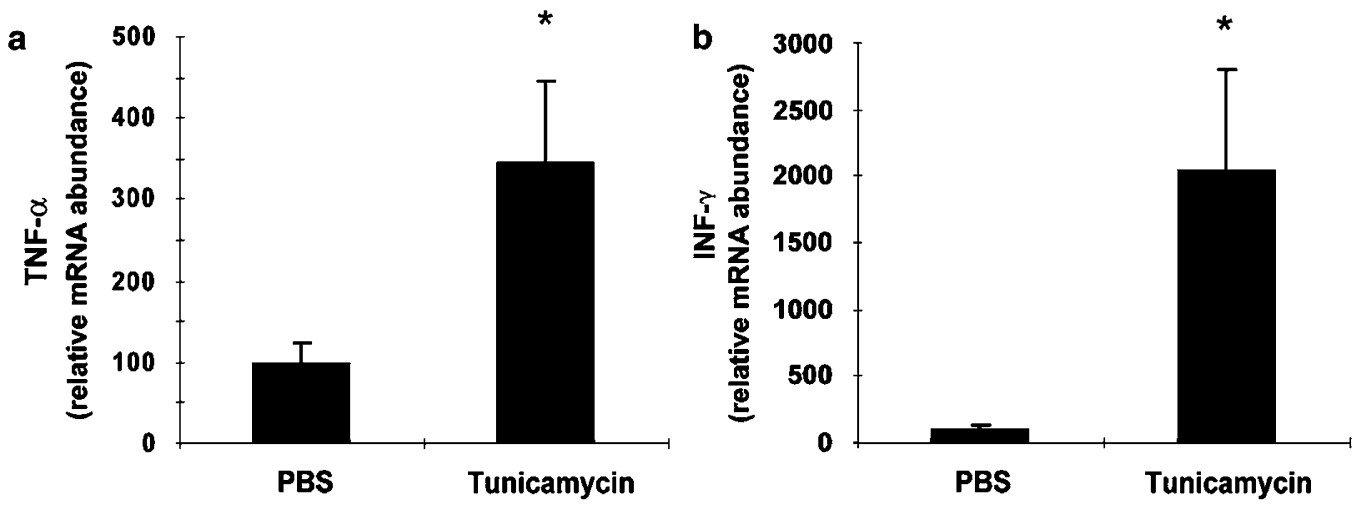

Figure 7 Increased hepatic TNF$\alpha$, IFN $-\gamma$ and IL-12 mRNA expression in livers of mice with tunicamycin-induced ER stress. Tunicamycin ( $200 \mathrm{ng} / \mathrm{g}$ body weight) was injected i.p. two times a week. After 4 weeks, basal expression of the proinflammatory ( $\mathrm{TH} 1)$ cytokines TNF- $\alpha(\mathbf{a})$ and IFN- $\gamma$ (b) and the anti-inflammatory cytokine, IL-4 (c), were measured in liver tissues by real time PCR. After 4 weeks of tunicamycin treatment, some mice were injected i.p. with a single dose of $E$. coli LPS $(20 \mu \mathrm{g} /$

C

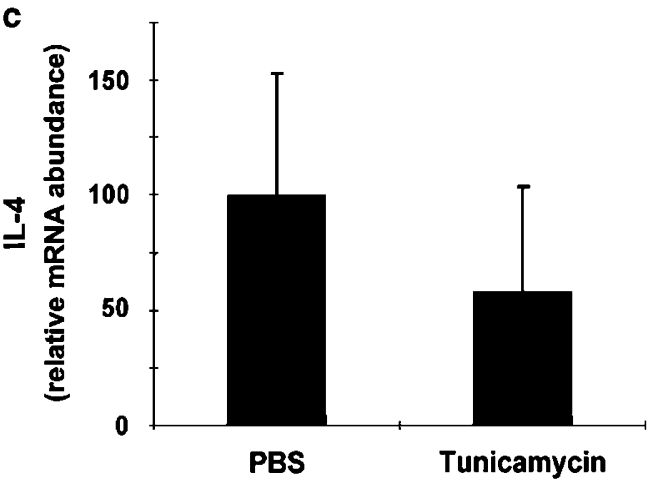

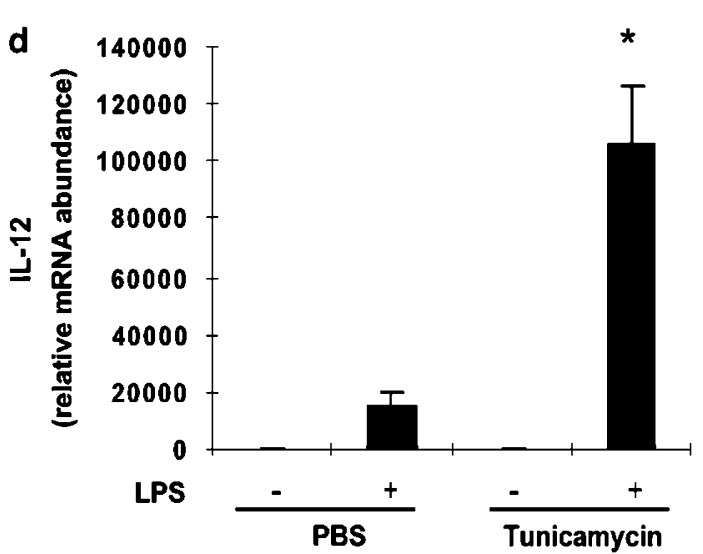
mouse) or PBS and then killed after $6 \mathrm{~h}$ to obtain liver tissue. Total liver RNA was extracted; mRNA expression of the proinflammatory cytokine IL-12 (d), was measured by real time PCR. In all experiments, ${ }^{*} P<0.05$ for tunicamycin-treated mice compared to PBS-treated mice ( $n=4$ mice/group).

hepatocyte CD1d. Thus, it is plausible (albeit unproven) that mice and humans with fatty livers exhibit similar defects in CD1d-mediated responses. Consistent with this concept, in both mice and humans, obesity, a major risk factor for hepatic steatosis, is strongly associated with conditions, such as autoimmunity and cancer, which typically increase as NKT cell function declines. ${ }^{14,58,59}$ Further research is needed to explore how obesity might reconfigure hepatic immune responses, given this novel evidence that links hepatic ER stress and fat accumulation with dysregulation of hepatic innate immunity.

\section{ACKNOWLEDGEMENT}

This work was supported by NIH grants RO1 DK053792-05 (A.M.D.).

1. Brigl M, Brenner MB. CD-1: antigen presentation and $T$ cell function. Annu Rev Immunol 2004;22:817-890.

2. Racanelli $\mathrm{V}$, Rehermann B. The liver as an immunological organ Hepatology 2006;43(2 Suppl 1):S54-S62.

3. Geissmann F, Cameron TO, Sidobre S, et al. Intravascular immune surveillance by CXCR6+ NKT cells patrolling liver sinusoids. PLoS Biol 2005;3:e113.

4. Matsuda JL, Naidenko OV, Gapin L, et al. Tracking the response of natural killer $T$ cells to a glycolipid antigen using CD1d tetramers. J Exp Med 2000;192:741-754.

5. Hammond KJ, Pellicci DG, Poulton LD, et al. CD1d-restricted NKT cells: an interstrain comparison. J Immunol 2001;167:1164-1173.

6. Gapin L, Matsuda JL, Surh CD, et al. NKT cells derive from doublepositive thymocytes that are positively selected by CD1d. Nat Immunol 2001;2:971-978
7. Benlagha $K$, Kyin $T$, Beavis $A$, et al. A thymic precursor to the NK T cell lineage. Science 2002;296:553-555.

8. Pellicci DG, Hammond KJ, Uldrich AP, et al. A natural killer T (NKT) cell developmental pathway ilnvolving a thymus-dependent NK11(-)CD4(+) CD1.d-dependent precursor stage. J Exp Med 2002;195:835-844.

9. Halder RC, Kawamura T, Bannai M, et al. Intensive generation of NK1.1extrathymic $T$ cells in the liver by injection of bone marrow cells isolated from mice with a mutation of polymorphic major histocompatibility complex antigens. Immunology 2001;102: 450-459.

10. Kameyama $\mathrm{H}$, Kawamura $\mathrm{T}$, Naito $\mathrm{T}$, et al. Size of the population of CD4+ natural killer T cells in the liver is maintained without supply by the thymus during adult life. Immunology 2001;104:135-141.

11. Beckman EM, Porcelli SA, Morita CT, et al. Recognition of a lipid antigen by CD1-restricted alpha beta+ T cells. Nature 1994;372: 691-694.

12. Rauch J, Gumperz J, Robinson C, et al. Structural features of the acyl chain determine self-phospholipid antigen recognition by a CD1d-restricted invariant NKT (iNKT) cell. J Biol Chem 2003;278: 47508-47515.

13. Kawano T, Cui J, Koezuka Y, et al. CD1d-restricted and TCR-mediated activation of valpha14 NKT cells by glycosylceramides. Science 1997;278:1626-1629.

14. Kita $\mathrm{H}$, Naidenko OV, Kronenberg $\mathrm{M}$, et al. Quantitation and phenotypic analysis of natural killer T cells in primary biliary cirrhosis using a human CD1d tetramer. Gastroenterology 2002;123:1031-1043.

15. Bradbury A, Belt KT, Neri TM, et al. Mouse CD-1 is distinct from and coexists with TL in the same thymus. EMBO J 1988;7:3081-3086.

16. Balk SP, Bleicher PA, Terhorst C. Isolation and expression of CDNA encoding the murine homologues of CD-1. J Immunol 1991;146: 768-774.

17. Martin LH, Calabi F, Lefebvre FA, et al. Structure and expression of the human thymocyte antigens CD1a, CD1b, and CD1c. Proc Natl Acad Sci USA 1987;84:9189-9193. 
18. Martin LH, Calabi F, Milstein C. Isolation of CD-1 genes: a family of major histocompatibility complex-related differentiation antigens. Proc Natl Acad Sci USA 1986;83:9154-9158.

19. Calabi F, Milstein C. A novel family of human major histocompatibility complex-related genes not mapping to chromosome 6. Nature 1986;323:540-543.

20. Calabi F, Jarvis JM, Martin L, et al. Two classes of CD-1 genes. Eur J Immunol 1989;19:285-292.

21. Calabi F, Belt KT, Yu CY, et al. The rabbit CD-1 and the evolutionary conservation of the CD-1 gene family. Immunogenetics 1989;30: 370-377.

22. Rhind SM, Dutia BM, Howard CJ, et al. Discrimination of two subsets of CD-1 molecules in the sheep. Vet Immunol Immunopathol 1996;52:265-270

23. Gumperz JE, Roy C, Makowska A, et al. Murine CD1d-restricted T cell recognition of cellular lipids. Immunity 2000;12:211-221.

24. Shamshiev A, Gober HJ, Donda A, et al. Presentation of the same glycolipid by different CD-1 molecules. J Exp Med 2002;195: 1013-1021.

25. Kjer-Nielsen L, Borg NA, Pellicci DG, et al. A structural basis for selection and cross-species reactivity of the semi-invariant NKT cell receptor in CD1d/glycolipid recognition. J Exp Med 2006;203:661-673.

26. Mattner J, Debord KL, Ismail N, et al. Exogenous and endogenous glycolipid antigens activate NKT cells during microbial infections. Nature 2005;434:525-529.

27. Brozovic S, Nagaishi T, Yoshida M, et al. CD1d function is regulated by microsomal triglyceride transfer protein. Nat Med 2004;10: 535-539.

28. Mendiratta SK, Martin WD, Hong $S$, et al. CD1d1 mutant mice are deficient in natural T cells that promptly produce IL-4. Immunity 1997;6:469-477.

29. McNab FW, Berzins SP, Pellicci DG, et al. The influence of CD1d in postselection NKT cell maturation and homeostasis. J Immunol 2005;175:3762-3768.

30. Skold M, Xiong X, Illarionov PA, et al. Interplay of cytokines and microbial signals in regulation of CD1d expression and NKT cell activation. J Immunol 2005;175:3584-3593.

31. Guebre-Xabier M, Yang S, Lin HZ, et al. Altered hepatic lymphocyte subpopulations in obesity-related murine fatty livers: potential mechanism for sensitization to liver damage. Hepatology 2000;31: 633-640.

32. Li Z, Soloski MJ, Diehl AM. Dietary factors alter hepatic innate immune system in mice with nonalcoholic fatty liver disease. Hepatology 2005;42:880-885.

33. Elinav E, Pappo O, Sklair-Levy M, et al. Amelioration of non-alcoholic steatohepatitis and glucose intolerance in ob/ob mice by oral immune regulation towards liver-extracted proteins is associated with elevated intrahepatic NKT lymphocytes and serum IL-10 levels. J Pathol 2006;208:74-81.

34. Seki S, Habu Y, Kawamura T, et al. The liver as a crucial organ in the first line of host defense: the roles of Kupffer cells, natural killer (NK) cells and NK1.1 Ag+ T cells in T helper 1 immune responses. Immunol Rev 2000;174:35-46.

35. Chen $\mathrm{H}$, Huang $\mathrm{H}$, Paul WE. NK1.1+ CD4+ T cells lose NK1.1 expression upon in vitro activation. J Immunol 1997;158:5112-5119.

36. Wilson MT, Johansson C, Olivares-Villagomez D, et al. The response of natural killer $\mathrm{T}$ cells to glycolipid antigens is characterized by surface receptor down-modulation and expansion. Proc Natl Acad Sci USA 2003;100:10913-10918.

37. Maher JJ, Bissell DM, Friedman SL, et al. Collagen measured in primary cultures of normal rat hepatocytes derives from lipocytes within the monolayer. J Clin Invest 1988;82:450-459.

38. Yang L, Magness ST, Bataller R, et al. NF-kappaB activation in Kupffer cells after partial hepatectomy. Am J Physiol Gastrointest Liver Physiol 2005;289:G530-G538.
39. Bilenki L, Wang S, Yang J, et al. NK T cell activation promotes Chlamydia trachomatis infection in vivo. J Immunol 2005;175: 3197-3206.

40. Dignam JD, Lebovitz RM, Roeder RG. Accurate transcription initiation by RNA polymerase II in a soluble extract from isolated mammalian nuclei. Nucleic Acids Res 1983;11:1475-1489.

41. Licato LL, Keku TO, Wurzelmann Jl, et al. In vivo activation of mitogenactivated protein kinases in rat intestinal neoplasia. Gastroenterology 1997;113:1589-1598.

42. Burant CF, Sreenan S, Hirano K, et al. Troglitazone action is independent of adipose tissue. J Clin Invest 1997;100:2900-2908.

43. Bartels ED, Lauritsen M, Nielsen LB. Hepatic expression of microsomal triglyceride transfer protein and in vivo secretion of triglyceride-rich lipoproteins are increased in obese diabetic mice. Diabetes 2002;51:1233-1239.

44. Harding HP, Calfon M, Urano F, et al. Transcriptional and translational control in the Mammalian unfolded protein response. Annu Rev Cell Dev Biol 2002;18:575-599.

45. Ozcan U, Cao Q, Yilmaz E, et al. Endoplasmic reticulum stress links obesity, insulin action, and type 2 diabetes. Science 2004;306:457-461.

46. Arase H, Arase N, Nakagawa K, et al. NK1.1+ CD4+ CD8 - thymocytes with specific lymphokine secretion. Eur J Immunol 1993;23:307-310.

47. Gumperz JE, Miyake S, Yamamura T, et al. Functionally distinct subsets of CD1d-restricted natural killer T cells revealed by CD1d tetramer staining. J Exp Med 2002;195:625-636.

48. Sidobre $\mathrm{S}$, Hammond KJ, Benazet-Sidobre L, et al. The T cell antigen receptor expressed by Valpha14i NKT cells has a unique mode of glycosphingolipid antigen recognition. Proc Natl Acad Sci USA 2004;101:12254-12259.

49. Ji C, Kaplowitz N. Betaine decreases hyperhomocysteinemia, endoplasmic reticulum stress, and liver injury in alcohol-fed mice. Gastroenterology 2003;124:1488-1499.

50. Gu F, Nguyen DT, Stuible M, et al. Protein-tyrosine phosphatase 1B potentiates IRE1 signaling during endoplasmic reticulum stress. J Biol Chem 2004:279:49689-49693.

51. Kremer M, Hines IN, Milton RJ, et al. Favored T helper 1 response in a mouse model of hepatosteatosis is associated with enhanced T cell-mediated hepatitis. Hepatology 2006;44:216-227.

52. Elinav $E$, Pappo O, Sklair-Levy $M$, et al. Adoptive transfer of regulatory NKT lymphocytes ameliorates non-alcoholic steatohepatitis and glucose intolerance in ob/ob mice and is associated with intrahepatic CD8 trapping. J Pathol 2006;209:121-128.

53. Arase $\mathrm{H}$, Arase $\mathrm{N}$, Kobayashi $\mathrm{Y}$, et al. Cytotoxicity of fresh NK1.1+ T cell receptor alpha/beta+ thymocytes against a CD4+8+ thymocyte population associated with intact Fas antigen expression on the target. J Exp Med 1994;180:423-432.

54. Kawano T, Cui J, Koezuka Y, et al. Natural killer-like nonspecific tumor cell lysis mediated by specific ligand-activated Valpha14 NKT cells. Proc Natl Acad Sci USA 1998;95:5690-5693.

55. Norris S, Doherty DG, Collins C, et al. Natural T cells in the human liver: cytotoxic lymphocytes with dual T cell and natural killer cell phenotype and function are phenotypically heterogenous and include Valpha24-JalphaQ and gammadelta T cell receptor bearing cells. Hum Immunol 1999;60:20-31.

56. Karadimitris A, Gadola S, Altamirano M, et al. Human CD1d-glycolipid tetramers generated by in vitro oxidative refolding chromatography. Proc Natl Acad Sci USA 2001;98:3294-3298.

57. Zeng Z, Castano AR, Segelke BW, et al. Crystal structure of mouse CD-1: An MHC-like fold with a large hydrophobic binding groove. Science 1997;277:339-345.

58. Vergani D, Choudhuri K, Bogdanos DP, et al. Pathogenesis of autoimmune hepatitis. Clin Liver Dis 2002;6:727-737.

59. Kenna T, Golden-Mason L, Porcelli SA, et al. NKT cells from normal and tumor-bearing human livers are phenotypically and functionally distinct from murine NKT cells. J Immunol 2003:171:1775-1779. 